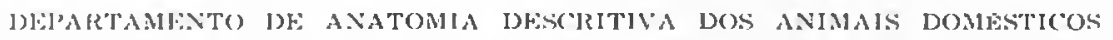
I)iretor: Pror, Dr, Orlando M. Paiva

\title{
REPARO A ORIGEM (INSERTIO SCAPULARIS) DO ... M. TERES MINOR EM BOVINOS *
}

(IREAIR TO 'THF: ORIGIN (INSERTIO SCAPULARIS) OF TIF .1. TERES MINOR IN BOVINESI

\author{
I. L. DE SANTIS PRADA \\ Pror. Assistente Doutor \\ Antonto Firnandes Filho \\ Pror. Assistente Doutor \\ VICENTE: BORELII \\ Pror. Assistente Doutor
}

\section{INTRODUCAOA E LITERATLRA}

Tendo observado que, no cão, o comportamento do insertio scapularis do $m$. teres minor diverge do estabelecido nos livros didáticos, PAIVA (1.946) admite a possibilidade de repetir-se, tal ocorrência, em outros animais domésticos. De fato, FErnandes \& SANTIS PRADA (1966 67), ao estudar material pertencente a eqüinos encontram oportunidade de assinalar a aludicia verificação. De nossa parte, buscando aclarar o problema no tocante aos bovinos, iniciamos preparaçāo de algumas peças que, uma vez dissecadas exibiram marcantes diferenças na disposição do $m$. teres minor, face às respectivas informações dos tratadistas. Por outro lado, não obtendo, da literatura especializada, nenhuma referência capaz de elucidar este fato, julgamos justificada a necessidade do presente reparo.

Passando a resumir as referências contidas nas Anatomias Veterinárias, a respeito da inserção escapular do $m$. teres minor, em bovinos, cabe-nos esclarecer que os AA. de modo geral, frente à quantidade de matéria a expor e ao número de espécies a considerar, tomam uma delas para modêlo nas descrições, habitualmente a eqüina, estabelecendo, para as restantes, apenas as divergências mais acentuadas. íubentende-se, portanto, que estas não

- Comunicado a $\mathrm{XXV}$ Conferéncia Anual da Socledade paulista de Medicina Vete. rinarla, realizada de 8 a 14 de setembro de 1970. em São Paulo. 
existam, isto $\dot{e}$, aceita-se o relato padrão, quando não mencionadas. Assim, a focada inserção far-se-ia:

a) na borda posterior c sôbre as cristas rugosas do colo da escápula (MONTANÉ \& Bourdelle - 1913);

b) na borda posterior da escápula e nas impressões lincares da parte baixa da fossa infra-espinhosa (LESBRE - 1922);

c) na parte distal da margem caudal da escápula c em direção à fossa infra-espinhosa (VARALDI - s. d.);

d) na metade distal da borda caudal da escápula (ELLe.NBERGER \& BAUM - 1932);

e) no terço distal da margem caudal da escápula (Martin 1904, Bruni - 1929, Brini \& ZimiMert - 1951, DobisersTEIN \& HOFFMANN - 1963);

f) na borda caudal da escápula (MoNGiarino - 1903, GonZÁLEZ Y GARCIA \& ÁLVAREZ - 1961);

g) nas linhas rugosas existentes nas porçōes distal e caudal da fossa infra-espinhosa e ainda $\mathrm{cm}$ parte da borda caudal da escápula (SISSON \& Grossmax - 1965);

h) na extremidade distal da porção central da escápula (SEIFERLE - 1954).

\section{MATERIAL E: MÉTODO}

O material desta pesquisa compreende 32 membros torácicos de bovinos; mais precisamente, valemo-nos de 16 pares, 8 obtidos de 7 fêmeas ( 6 adultas e 1 jovem) e 1 macho (jovem), de origem indiana e 8 , de 6 fèmeas (adultas) e 2 machos ( 1 advlto e 1 jovem), de origem européia. Os animais, de diferentes raças que discriminamos na Tabela I, procederam de várias regiōes do Eslado de Sāo Paulo e foram sacrificados na Faculdade de Medicina Veterinária da Universidade de São Paulo.

Para visualizar o $m$. teres minor, estando a peça a fresco ou já fixada $\mathrm{em}$ formol a $10 \%$, dela separávamos completamente os $\mathrm{mm}$. deltoide, infra-espinhoso, grande redondo e triceps braquial (cabeça longa). Completando a dissecceào, procediamos cuidadosamente à individualização de sua lâmina tendinea do que restava dos $\mathrm{mm}$. infra-espinhoso e triceps braquial.

Tomávamos, a seguir, da preparação, duas medidas, em linha reta, a partir do ponto mais caudal da borda da cavidade glenoide; uma delas, atingindo o ângulo caudal da escápula, permitiria avaliar-se a extensão da margem caudal do osso, enquanto a outra. 
alcançando a extremidade dorsal do feixe tendineo mais caudal, da lâmina aponeurótica do $m$. teres minor, estabeleceria o ponto culminante de origem dêsse músculo na aludida margem caudal da escápula.

Com a finalidade de comprovar a relação de continuidade entre as porções muscular e aponeurótica retiramos, de 1 caso, para feitura de cortes histológicos, fragmento da faixa de transição entre ambas, corando-os pelos métodos de H.E. e Mallory.

Preparamos também, para fins de documentação do trabalho, esçuema de uma das dissecçōes.

\section{RESLLTADOS}

O m. teres minor, localizado junto à margem caudal da escápula e caudo-lateralmente à articulação escápulo-umeral mostra-se, nos bovinos, bastante alongado e de aspecto irregular (Fig. 1). Exibe assim, em tôda a extensão, duas faces amplas, medial e lateral, relacionadas respectivamente, mediante aponevroses vistas a recobri-las, com os $\mathrm{mm}$. triceps braquial (cabeça longa) e infra-espinhoso, afora uma terceira, afilada, de situação cranio-medial que, limitando-se à porção do músculo adjacente à escápula, repousa sõbre particular área da fossa infra-espinhosa, bem delimitada por duas linhas rugosas; estas, partindo das imediaçōes da borda caudal da escápula, aproximadamente a seu meio comprimento, adentram-se na citada fossa, em sentido cranio-ventral, afastando-se progressivamente, uma da outra e ambas, da aludida borda, para, de novo, se avizinharem, ao final de seu percurso, nas proximidades da margem lateral da cavidade glenoide. A metade distal do ventre muscular apresenta ainda, caudalmente, outra face, losangular, à qual se aplica diretamente o m. deltoide.

$O$ encontro das faces medial e lateral com a cranio-medial é representado por duas arestas de posições relativas designadas, por ordem, caudo-medial e crânio-lateral, desenhadas segundo as descritas linhas rugosas da fossa infra-espinhosa. Estas arestas fundem-se dorsal e ventralmente dando continuidade, a êste nivel, à borda cranial de contato das referidas faces medial e lateral. Por outro lado, o limite destas com a caudal é dado pelas respectivas margens caudo-medial $c$ caudo-lateral que convergem dorsalmente e se prolongam na aresta caudal, de união das duas superfícies inicialmente citadas.

Particularizando as estruturas relacionadas com a origem do focado músculo, destacamos a presença de duas lâminas aponeuróticas que, inseridas nas correspondentes e já mencionadas linhas rugosas da fossa infra-espinhosa revestem, conforme se adiantou, as faces medial e lateral do ventre muscular, a elas aderindo for- 


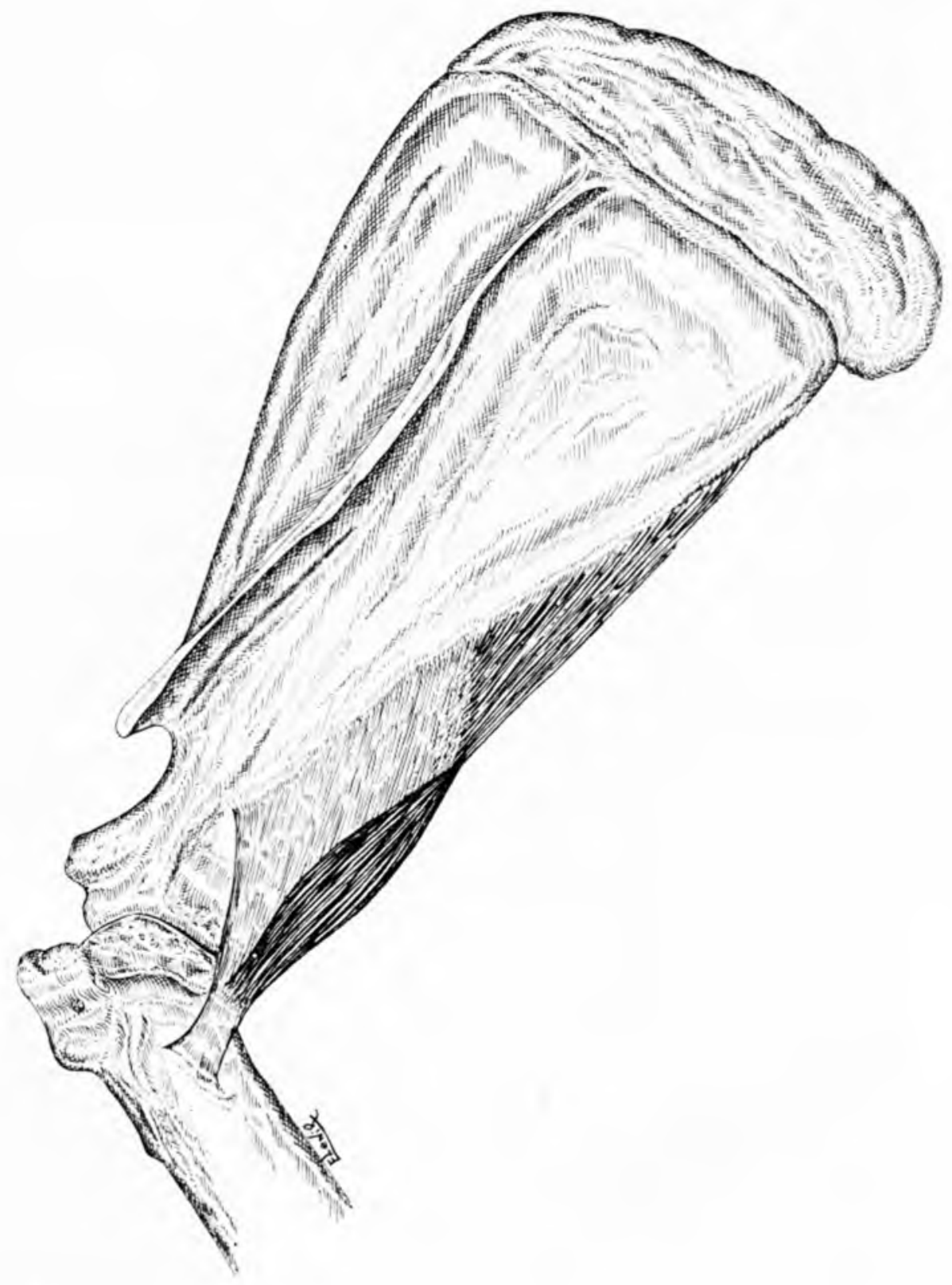

Fig. 1 - Insercân escapular (o) m. tệs minor, cm bovino. 
temente; no sentido caudal, junto à margem de uniāo destas faces, as aponeuroses se fundem em lâmina única encontrada a alcançar, por intermédio de feixes tendineos tanto mais longos quanto mais caudais, a borda caudal da escápula, desde o limite inferior do quarto proximal até as imediações de seu meio comprimento.

Em resumo, a origem (insertio scapularis) do $m$. teres minor faz-se por meio de feixes tendíneos tanto mais longos quanto mais caudais, na margem caudal da escápula (desde o limite inferior do quarto proximal até meio comprimento) e na fossa infraespinhosa, mediante aponeuroses, em duas linhas rugosas que atingem as imediações de seu limite ventral. Esclarecemos também que reduzido conjunto de fibras musculares, nāo destacado do ventre principal, parte da pequena tuberosidade existente nas vizinhanças da borda lateral da cavidade glenoide.

No tocante aos cortes histolćgicos efetuados, elucidamos que puderam comprovar a relaçāo de continuidade entre as partes muscular e aponcurótica.

'l' B B F I. A I

Quadro sinótio das Obsorvacöes inidiendo, no material estudado, as distanncias (cm.l. em línha reta. do ponto mais ritudal da borda da cavidade glenolde a angulo [audal da escapula $(A)$ e a extremidade dorsal do feise tendinco mais ('audal, da lamina aponeurótical do m. perex minor (b).

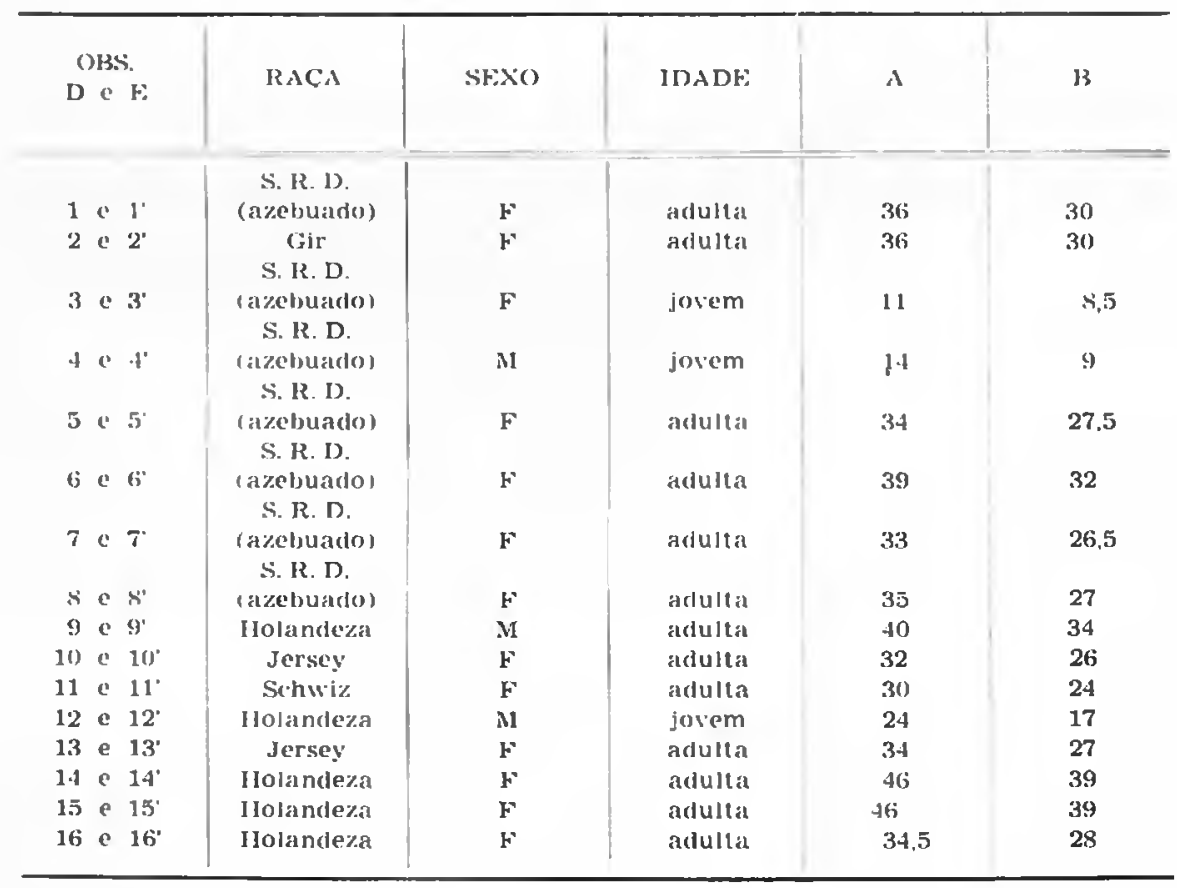




\section{COMENTARIOS E CONCLUSÓES}

Cumpre-nos ressaltar, de início, que PaIva bem sugeriu fosse feita revisāo da origem (insertio scapulariss) do $m$. teres minor nos mamiferos domésticos, pois encontramos em bovinos, como FERNANDES \& SANTIS PRADa, no cavalo, razões para seu processamento. De fato, o aspecto morfológico de nossas preparações mostrou-se, sempre, diverso do referido pelos tratados de Anatomia Veterinária, por vêzes discordantes entre si. De tal sorte, julgamos imprecisos os dizeres dos AA. que apontam a mencionada origem a efetuar-se na borda caudal da escápula (Monginindino, Gonzáles y GArciı \& Álvarez); nesta e sôbre as cristas rugosas do colo da escápula (MONTANÉ \& BouRdelle); na focada borda e nas impressões lineares da parte baixa da fossa infra-espinhosa (LesBre); nas linhas rugosas existentes nas porções distal c caudal da fossa infra-espinhosa e, ainda, em parte da borda caudal da escápula (Sisson \& Grossman). Por outro lado, entendemos como incorretas as descrições que a indicam a realizar-se na extremidade distal da porção central da escápula (SEIrERLE), bem como na margem caudal do osso, em sua metade distal (ELLENBERGER \& BAUM); em seu terço distal (Martin, Bruni, Bruni \& Zimimerl, Dobberstein \& HofFMnNN); em sua parte distal e em direção à fossa infra-espinhosa (VARALDI).

Segundo apuramos, a focada origem faz-se por meio de feixes tendíneos tanto mais longos quanto mais caudais, na margem caudal da escápula (desde o limite inferior do quarto proximal até meio comprimento) e na fossa infra-espinhosa, mediante aponeuroses, em duas linhas rugosas vistas a atingirem as imediaçōes de seu limite ventral; verificamos, ainda, que reduzido conjunto de fibras musculares prende-se em pequena tuberosidade existente nas proximidades da borda lateral da cavidade glenoide.

\section{SUMMARY}

The bovine's teres minor muscle was dissected in 32 1horacic limbs in order to study its origin (Insertio sccupularis). Its arises from the inferior limit of the proximal fourth to the middle of the caudal border of the scapula and from two oblique muscular imprinties of the infraspinous fossa.

Sex, age and breed seem not 10 influence the anatomical disposition of the teres minor muscle.

\section{REFFRENCIAS BIBIIOGRÁFICAS}

BRUNI, A. C. - In ZIMMERL. U. - Tratfute de entomin reterimeriu. $\checkmark .1$. Milano, Franceseo Vallatdi, 1929, p. 678.

BRUNI. A. C. \& ZIMMERL. U. - Anatomin degli amimall domestim. v.1. Milano, Francesen Vallardi. 1951. p. 410. 
DOBBERSTEIN, J. \& HOFFMANN, G. - Lehrbuch der vergleichenden Amatomie der Hanstiere. '.2. Leipzig. S. Hirzel, 1963. p. 137.

ELI.ENBERGF.R. W. \& BAUM, H. - Hundbuch der vergleichenden Anutomie dev Haustieve, v.1. 17 Auf. Berlin, Julius Springer, 1932, p. 2.4.

FEIRNANDFS FILHO. A. \& SANTIS PRADA. I. L. de - Reparo à origem (insertio scapularis) do m. teres minon no cavalo. Rev. Fuc. Med. vet., S. Paulo, $7(3): 527-533,196667$.

GONZALEZ Y GARCIA. J. \& ÁLVAREZ. R. G. - Amatomin compuradu de los Animules domesticos. 7" ed. Madrid. Gráficas Canales, 1961. p. 345.

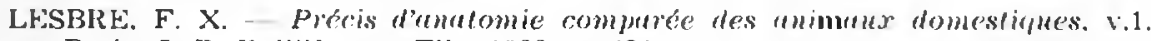
Paris, J. B. Baillière et Fils, 1922, ๒. 431.

MARTIN, P. - Lehrbuch der Anutomie der Houstiere. v.2. Stutgart. Schickhardt \& Ebner. 1904. p. 430.

MONGIARDINO, T. - Trattato di unutomin topogruficu dei memiferi domestici. Torinn, Luigi Delgrosso, 1903, p. 219.

MONTANE. L. \& BOURDELI.F. E. - Amulomie regiomale des amimanx domestiques. v.1. Paris, J. B. Baillière et Fils, 1913, p. 630.

PAIVA. O. M. - Reparo à origem (insertio scapuluris) do m. teres minor no cão doméstico. Ret. Fuc. Med. vet., S. Paulo. 3(3):15-27, 1946.

SEIFERI,F, \&. - In NICKEL, R.; SCHUMMER, A. \& SEIFERLE, F. Lehrbuch der Anatomie der Hanstiere. r.1. Berlin. Paul Parey, 1954. p. 385.

SISSON. S. \& GROSSMAN, J. D. - Auntomm de los amimales domestiros. $4^{4}$ ed. Barcelona, Salvat Fditores, 1965. p. 283.

VARALDI. L. - I" BOSSI, V.; CARADONNA, G. B.; SPAMPANI. G.; VARAIDI. L. \& ZIMMERL, U. - Trutluto di unrtomia veterinuriu. $\because .1$. Milano. Franceseo Vallardi, s.d., p. 608. 